\title{
ANALISIS PERHITUNGAN KERJA RELAY GANGGUAN TANAH PADA FEEDER DI GARDU INDUK 150 KV SEI HARAPAN PT XYZ BATAM
}

\section{ANALYSIS OF CALCULATION RELAY GROUND FAULT IN POWER HOUSE FEEDER 150 KV SEI HARAPAN PT. XYZ BATAM}

\author{
Chandra Noviansyah ${ }^{1}$, Muhammad Irsyam ${ }^{2}$, \\ ${ }^{1,2}$ Program Studi Teknik Elektro, Fakultas Teknik Universitas Riau Kepulauan Batam \\ 1. chandrayansyah@gmail.com, ${ }^{2}$ irsyam.muaz1@gmail.com
}

\begin{abstract}
Abstrak
Pada system proteksi, relai gangguan tanah merupakan bagian terpenting di suatu peralatan. Relai gangguan tanah harus dilakukan pengaturan agar dapat bekerja dengan baik dan handal dalam mengatasi suatu gangguan. Gangguan hubung singkat sering terjadi pada jaringan $20 \mathrm{KV}$, antar fasa, atau gangguan hubung singkat fasa ke tanah. jika proteksi kurang baik maka dapat menyebabkan pemadaman yang meluas dan rusaknya peralatan. Oleh karena itu digunakan relai gangguan tanah atau ground fault relay pada suatu peralatan, salah satunya pada feeder. Perhitungan setting kerja relai gangguan tanah di dapatkan dari nilai setting yang di terapkan dan karakteristik waktu yang digunakan. Setelah dilakukan perhitungan dan menganalisa didapatkan perbedaan atau perselisihan waktu kerja relai. Dan dari hasil penelitian diketahui bahwa relai gangguan tanah masih dalam kondisi yang sesuai dengan yang telah d setting di lapangan.
\end{abstract}

Kata kunci : Relay proteksi ground fault

\section{PENDAHULUAN}

Penggunaan tenaga listrik saat ini semakin maju, tidak hanya penerangan dan keperluan industri, tetapi sudah sampai untuk kebutuhan rumah tangga yang sekecil kecilnya. Dengan demikian suatu sistem tenaga listrik sangat di harapkan dapat menyalurkan daya secara terus - menerus kepada konsumen dan faktor yang harus diperhatikan adalah sistem transmisi, tegangan dan frekuensi yang konstan maupun keseimbangan sistem.

Sistem transmisi tiga phasa sangat mempengaruhi keseimbangan sistem, apabila terjadi ketidakseimbangan beban ataupun sistem maka akan berdampak negatif. Ketidakseimbangan sistem dapat disebabkan pada impedansi phasa yang tidak seimbang. Hantaran udara formasi dari ketiga hantaran pada tiga phasa akan mempengaruhi impedansi masing - masing phasa tersebut. Kondisi phasa yang tidak seimbang umumnya terjadi pada jaringan pendistribusian, yang cenderung di hubungkan dengan transformator dan jaringan distribusi dan beban rumah tangga satu phasa. [2]

Untuk menyeimbangkan atau agar tidak terjadi gangguan pada sistem kelistrikan, maka di butuhkan sistem proteksi. Sistem proteksi ini akan bekerja apabilan terjadinya gangguan pada sistem kelistrikan, sistem proteksi bekerja dan akan melepaskan circuit breaker (CB) atau pemutus tenaga (PMT).

Sistem proteksi pada gardu induk Sei Harapan bagian feeder cendrawasih atau penyulang sisi 20 KV menggunakan relay ground fault 
atau relay gangguan tanah. Relay yang di gunakan adalah type sepam $1000+$.

Relay gangguan tanah akan bekerja apabila terjadi aliran arus urutan nol (residu) pada relay gangguan tanah. untuk mendapatkan arus yang meresidu ini ada beberapa metode yang harus dipergunakan dan salah satunya ada yang tidak seimbangnya salah satu fasa akibat gangguan fasa ke tanah. [4]

Dalam proses pengujian kehandalan relay tersebut perlu di lakukan perhitungan waktu tunda kerja relay. Dengan demikian dapat diketahui seberapa cepat relay tersebut melepaskan PMT.

Berdasarkan latar belakang diatas dapat di ketahui bahwa rumusan masalahnya adalah untuk mengetahui hasil pengujian kerja relay ground fault terhadap gangguan fasa ke tanah pada feeder cendrawasih, dan apakah feeder cendrawasih masih layak digunakan dan bekerja sesuai karakteristik standard inverse yang telah di terapkan oleh PT. XYZ Batam.

\section{LANDASAN TEORI}

\section{A. Sistem kelistrikan PT. XYZ Batam}

Sistem kelistrikan PT. XYZ Batam merupakan kesatuan dari beberapa $s u b$ sistem yang terhubung menjadi satu dan merupakan pendukung utama dalam sistem ketenagalistrikan, baik pada sisi pembangkit, transmisi, maupun distribusi.

Sub sistem adalah suatu tempat atau instalasi yang berfungsi untuk menerima dan menyalurkan tenaga listrik dari suatu pusat pembangkit listrik ke gird atau jaringan. Pada sub sistem terdapat peralatan-peralatan listrik yang di susun sedemikan rupa sehingga membentuk pola atau konfigurasi tertentu. Gardu induk merupakan alat penghubung listrik dari jaringan transmisi ke jaringan distribusi primer.

\section{Saluran Transmisi}

Saluran transmisi merupakan media yang digunakan untuk mentransmisikan tenaga listrik dari dari pembangkit listrik sampai ke distribusi hingga sampai pada konsumen pengguna listrik tenaga listrik di transmisikan oleh suatu bahan bakar konduktor yang mengalirkan tipe saluran transmisi listrik penyaluran tenaga listrik pada transmisi menggunakan arus bolak balik (AC) ataupun arus searah (DC). [5]

Saluran transmisi dengan menggunakan sistem arus bolak balik tiga fasa merupakan sistem yang di gunakan di PT XYZ Batam, yaitu sistem tegangan pada jaringan transmisi $150 \mathrm{KV}$. Jaringan tegangan tinggi di PT. XYZ Batam hanya terdiri dari saluran udara tegangan tinggi (SUTT). [2]

\section{Sistem Distribusi $20 \mathrm{KV}$}

Sistem distribusi 20KV adalah keluaran dari transformator daya dikumpulkan pada Bus $20 \mathrm{KV}$ di kubikel Gardu Induk untuk kemudian di distribusikan melalui beberapa penyulang 20KV ke konsumen dengan jaringan berupa Saluran Udara Tegangan Menengah (SUTM) atau Saluran Kabel Tegangan Menengah (SKTM).

Seringnya gangguan pentanahan di jaringan menyebabkan 
sering pula relai proteksi bekerja dan sesering itu pula transformator daya menderita pukulan hubung singkat yang dapat memperpendek umur transformator daya tersebut. Dengan besarnya kapasitas sistem $150 \mathrm{KV}$, boleh dikatakan hubung singkat di Bus 20KV tergantung dan dibatasi oleh besarnya kapasitas transformator daya.

\section{Gardu Induk}

Gardu induk adalah pusat untuk menerima dan mengirim kembali tenaga listrik menuju jalur - jalur yang sudah ditentukan. Peralatanperalatan pada gardu induk antara lain:

- Busbar atau rel

Busbar merupakan titk pertemuan antara transformator tenaga, saluran udara tegangan tinggi, saluran kabel tegangan tinggi dan peralatan listrik lainnya yang berfungsi untuk menerima dan menyalurkan tenaga listrik. Busbar yang digunakan di gardu induk sei harapan adalah busbar ganda.

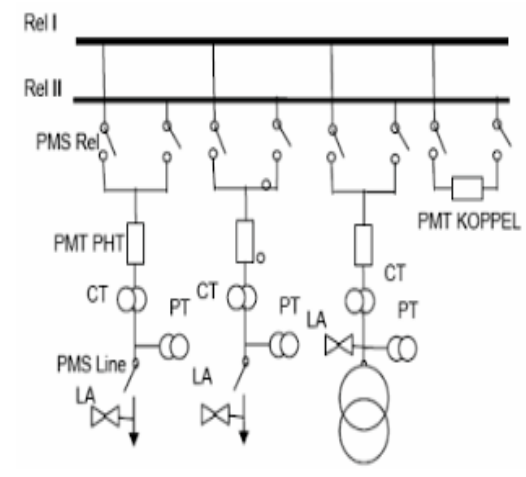

Gambar1. Sistem busbar ganda
- Lighning Arrester

Pada umumnya disebut Arrester yang berfungsi sebagai pengaman instalasi (peralatan listrik pada instalasi Gardu Induk) dari gangguan tegangan lebih akibat sambaran petir (ligthning Surge) maupun oleh surja hubung (switching surge).

- Transformator Ukur

Untuk proses pengukuran digardu induk diperlukan tranformator instrument, tranformator instrument ini dibagi atas dua kelompok yaitu transformator tegangan, transformator arus dan transformator bantu.

- Sakelar Pemisah (PMS)

Sakelar ini berfungsi untuk mengisolasikan peralatan listrik dari peralatan lain atau instalasi lain yang bertegangan. PMS ini boleh dibuka atau ditutup hanya pada saat tidak berbeban.

- Sakelar Pemutus Tenaga (PMT)

Sakelar ini berfungsi untuk menghubungkan dan memutuskan sistem pada saat terbebani (pada kondisi arus beban normal atau pada saat terjadi arus gangguan). Pada waktu menghubungkan atau memutus beban, akan terjadi tegangan recovery yaitu suatu fenomena tegangan lebih dan busur api, oleh karena itu sakelar pemutus dilengkapi dengan media peredam busur api, seperti media udara dan gas SF6.

- Sakelar Pentanahan

Sakelar ini untuk menghubungkan kawat konduktor dengan tanah atau bumi yang berfungsi untuk menghilangkan atau mentanahkan tegangan induksi pada konduktor pada saat akan dilakukan perawatan atau pengisolasian 
suatu sistem. Sakelar Pentanahan ini dibuka dan ditutup hanya apabila sistem dalam keadaan tidak bertegangan.

- Kompensator

Kompensator didalam sistem penyaluran tenaga listrik disebut pula alat pengubah fasa yang dipakai untuk mengatur jatuh tegangan pada saluran transmisi atau transformator, dengan mengatur daya reaktif atau dapat pula dipakai untuk menurunkan rugi daya dengan memperbaiki faktor daya. Alat tersebut ada yang berputar dan ada yang stationer, yang berputar adalah kondensator sinkron dan kondensator asinkron, sedangkan yang stationer adalah kondensator statis atau kapasitor shunt dan reaktor shunt.

- Relay Proteksi dan Papan Alarm (Announciator)

Relay proteksi yaitu alat yang bekerja secara otomatis untuk mengamankan suatu peralatan listrik saat terjadi gangguan, menghindari atau mengurangi terjadinya kerusakan peralatan akibat gangguan dan membatasi daerah yang terganggu sekecil mungkin. Kesemua manfaat tersebut akan memberikan pelayanan penyaluran tenaga listrik dengan mutu dan keandalan yang tinggi. Sedangkan papan alarm atau announciator adalah sederetan nama-nama jenis gangguan yang dilengkapi dengan lampu dan suara sirine pada saat terjadi gangguan.

\section{B. Beban Tak Seimbang}

Suatu beban tiga fasa seimbang apabila arus yang dihasilkan seimbang, bilamana beban tersebut dihubungkan dengan tegangan sistem yang seimbang, beban yang tak seimbang dapat ditandai dengan tidak seimbangnya arus yang mengalir pada sistem, kondisi ini dipengaruhi oleh tegangan yang dibangkitkan sistem tidak seimbang, impedansi fasanya tidak sama dan impedansi beban tidak sama.

Dalam perencanaan daya listrik, sistem direncanakan seimbang. Keseimbangan dimaksud disini adalah tegangan yang dibangkitkan seimbang dan impedansi perfasanya sama (impedansi penyalur). Munculnya ketidakseimbangan arus umumnya disebabkan oleh impedansi beban yang tidak sama perfasanya.

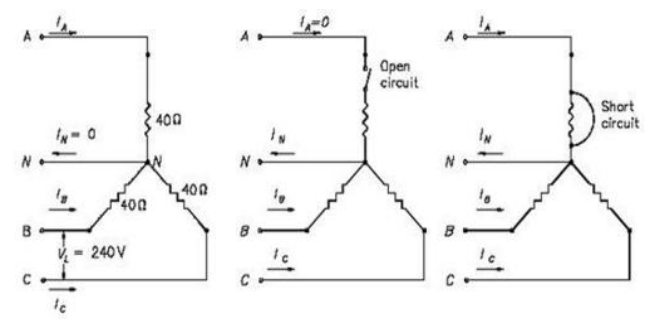

Gambar 2 Ketidakseimbangan beban karena gangguan [6]

\section{Impedansi Urutan}

Dalam setiap bagian rangkaian, jatuh tegangan yang disebabkan oleh arus dengan urutan tertentu tergantung pada impedensi bagian rangkaian itu terhadap arus dengan urutan tersebut. Impedansi setiap bagian suatu jaringan yang seimbang terhadap arus salah satu urutan dapat berbeda dengan impedansi terhadap arus dari urutan yang lain.

Impedansi suatu rangkaian yang hanya mengalir arus urutanpositif disebut impedansi terhadap arus urutan-positif. Demikian pula, 
bila hanya ada arus urutan negatif, impedansinya dinamakan impedansi terhadap arus urutan-negatif. Jika hanya ada arus urutan nol, impedansinya dinamakan impedansi terhadap arus urutan-nol.

\section{Transformator Arus}

Transformator arus (Current Transformator) berfungsi untuk mentransformasi-kan arus dari nilai yang besar (sisi primer) menjadi nilai yang rendah (sisi sekunder). Arus sekunder CT biasanya digunakan sebagai masukan untuk alat ukur atau/dan sistem proteksi. Hasil transformasi pada sisi primer menjadi sekunder adalah sesuai dengan nilai perbandingan atau rasio yang dimiliki oleh transformator arus tersebut. Rasio CT yang umum dipakai untuk pengukuran TM adalah:

$$
\frac{10-20}{5}, \frac{15-30}{5}, \frac{25-50}{5}, \frac{30-60}{5}, \frac{40-80}{5}
$$

dan lainnya.

Maksud dari rasio di atas adalah pada umumnya transformator arus pengukuran TM memiliki 2 pengukuran yaitu sisi low dan sisi high. Transformator arus dengan rating $\frac{150-300}{5}$, maka sisi low adalah $\frac{150}{5}$ dan sisi high $\frac{300}{5}$. adalah:

Fungsi dari transformator arus

1. Mengkonversi besaran arus pada sistem tenaga listrik dari besaran primer menjadi besaran sekunder untuk keperluan pengukuran sistem metering dan proteksi.

2. Mengisolasi rangkaian sekunder terhadap rangkaian primer, sebagai pengamanan terhadap manusia atau operator yang melakukan pengukuran.

3. Standarisasi besaran sekunder, untuk arus nominal 1 Amper dan 5 Amper.

Secara fungsi transformator arus dibedakan menjadi dua yaitu:

1. Transformator arus pengukuran Transformator arus pengukuran untuk metering memiliki ketelitian tinggi pada daerah kerja (daerah pengenalnya) 5\% $120 \%$ arus nominalnya tergantung dari kelasnya dan tingkat kejenuhan yang relatif rendah dibandingkan transformator arus untuk proteksi. Penggunaan transformator arus pengukuran untuk Ampermeter, Watt-meter, VARh-meter, dan $\cos \varphi$ meter.

2. Transformator arus proteksi

Transformator arus untuk proteksi, memiliki ketelitian tinggi pada saat terjadi gangguan dimana arus yang mengalir beberapa kali dari arus pengenalnya dan tingkat kejenuhan cukup tinggi. Penggunaan tranformator arus proteksi untuk relay arus lebih (GFR dan OCR), relay beban lebih, relay diferensial, relay daya dan relay jarak.

\section{E. Relay Proteksi}

Busbar dan diameter tidak terlepas dari kondisi abnormal yang disebut sebagai gangguan. Gangguan yang terjadi pada busbar dan diameter adalah gangguan yang bersifat destruktif. Apabila terjadi gangguan pada busbar atau diameter, maka kemungkinan terjadi kerusakan pada peralatan instalasi yang sangat besar. Di samping itu, keandalan 
sistem dalam menyalurkan pasokan daya juga akan terganggu.

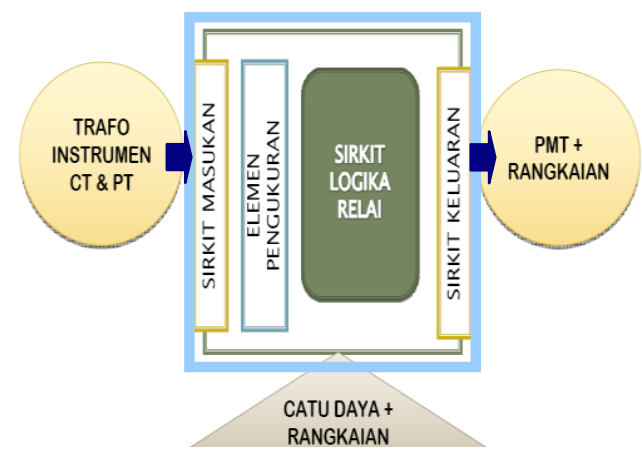

Gambar 3 Komponen Utama Relay Proteksi [4]

\section{Proteksi busbar/diameter} adalah suatu sistem proteksi yang berperanan penting dalam mengamankan gangguan yang terjadi pada busbar atau diameter. Sistem proteksi ini harus bekerja secara sensitif, selektif, cepat dan harus stabil untuk gangguan yang terjadi di luar daerah pengamanan busbar atau diameter. Sistem proteksi busbar dan diameter merupakan suatu sistem kolektif yang meliputi : transformator arus (CT) atau transformator tegangan (PT), relay proteksi, pemutus tenaga (PMT), dan rangkaian pengawatannya. Bagian bagian dari sistem proteksi ini dapat dilihat pada gambar 2.3 di atas.

Sistem proteksi memiliki fungsi utama, yaitu :

1. Mendeteksi adanya gangguan atau keadaan abnormal lainnya pada bagian sistem yang diamankannya.

2. Melepaskan bagian sistem yang terganggu, sehingga bagian sistem lainnya yang tidak mengalami gangguan dapat terus beroperasi.

\section{Relay Proteksi Gangguan Tanah (GFR)}

Gangguan tanah adalah terhubungnya konduktor fasa dengan beban atau tempat yang terhubung dengan tanah sehingga beban atau tempat tersebut bertegangan dan mengalirkan arus ketanah. Gangguan ini merupakan gangguan terbesar dari semua jenis gangguan sistem daya listrik. Karena itu pengaman terhadap gangguan tanah ini merupakan suatu hal yang terpenting.

Relay gangguan tanah (Ground Fault Relay) adalah pengaman terhadap gangguan tanah. Relay ini berfungsi untuk memproteksi SUTM terhadap gangguan antara fasa atau 3 fasa dan hanya bekerja pada satu arah saja. Karena rele ini dapat membedakan arah arus gangguan. Arus atau tegangan urutan nol (residu) merupakan penggerak relay ini. Sistem daya listrik pada umumnya titik netralnya ditanahkan, baik pentanahan langsung (Solid Grounded) maupun melalui impedansi, karena itu arus residu merupakan penggerak utama relay gangguan tanah. Tegangan residu dipergunakan biasanya pada sistem yang tidak ditanahkan. Relay gangguan tanah terarah (Directional Ground Fault Relay) mempergunakan arus dan tegangan residu.

Prinsip kerja GFR dapat digambarkan seperti gambar di bawah ini. 


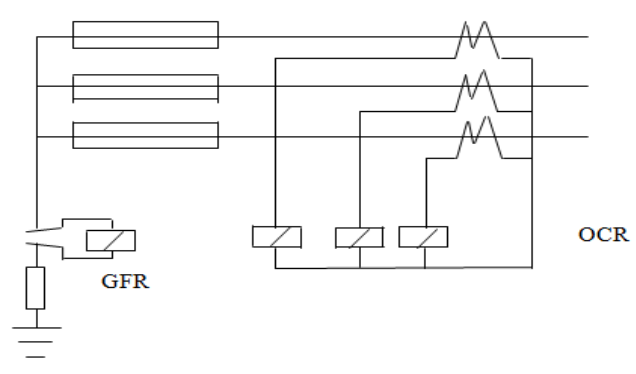

Gambar 4 Relay Hubung tanah pada pentanahan netral [4]

\section{Relay Sepam $1000+$}

Relay sepam 1000+ adalah relay proteksi yang berfungsi untuk melindungi sistem tenaga listrik dari gangguan. Gangguan yang dimaksud adalah gangguan fasa ketanah atau ground fault, gangguan arus lebih atau over current, tegangan lebih, tegangan rendah, frekuensi lebih, frekuensi rendah, dan bisa berfungsi sebagai recloser.

\section{Setting Relay Sepam 1000+}

Untuk memperoleh suatu jaringan tenaga listrik yang baik, maka salah satu faktor pendukungnya adalah kehandalan sistem proteksi. Alat proteksi yang umum digunakan pada jaringan tegangan menengah dan jaringan tegangan tinggi maka relay proteksi yang ada pada jaringan tersebut harus memenuhi syarat - syarat teknik dan parameter - parameter yang diberikan pada relay harus benar. Parameter dapat dibuat

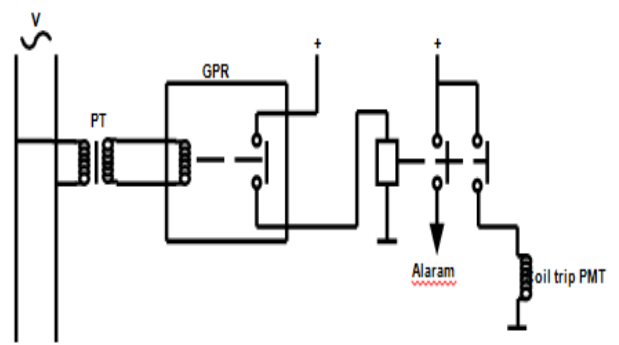

dengan mеnи pengaturan atau setting pada relay.
Dalam penyetelan relay yang digunakan perlu diperhatikan karakteristik relay yaitu standard inverse. Dalam penentuan nilai arus setting pada relay dapat digunakan dengan rumus berikut:

$I s=k$. In

Dimana:

$$
\begin{aligned}
& \text { Is }=\text { arus setting } \\
& \mathrm{k}=\text { faktor pabrik }(0.3 \mathrm{~s} / \mathrm{d} 24) \\
& \mathrm{In}=\text { arus nominal }
\end{aligned}
$$

\section{Karakteristik Inverse}

Karakteristik standard inverse merupakan pedoman yang digunakan dalam perhitungan waktu tunda kerja relay dapat dirumuskan sebagai berikut:

$\mathrm{t}=\frac{\mathrm{K}}{\left(\frac{l f}{I s}\right)^{\alpha}-1} \cdot \frac{T}{\beta}$

Dimana:

$\mathrm{t}=$ Waktu tunda kerja relay (second )

$\mathrm{T}=$ Karakteristik waktu tunda kerja relay ( second)

If $=$ Arus Injeksi $(A)$

Is $=$ Arus Setting (A)

$\mathrm{K}=$ Koefisien Values $(0,14)$

$\alpha=$ Alpha $(0,02)$

$\beta=\operatorname{Beta}(2,97)$

Karakteristik relay dapat dinyatakan dengan time multiple

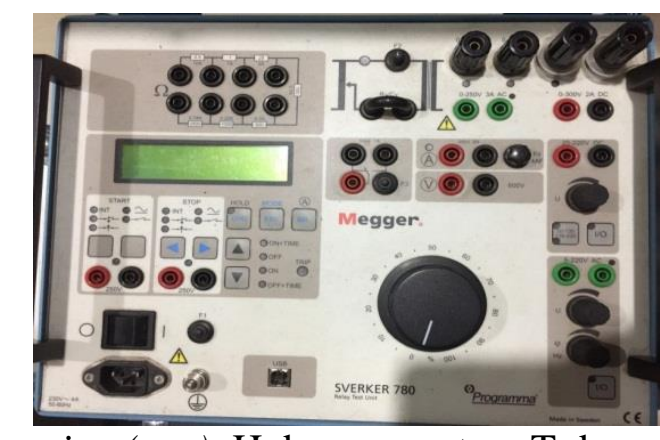

setting (tms). Hubungan antara $\mathrm{T}$ dan tms dapat dipaparkan melalui rumus berikut: 
$\operatorname{tms}=\frac{T}{\beta}$

Diamana :

tms = time multiple setting ( second)

$\mathrm{T}=$ karakteristik waktu tunda relay ( second)

$\beta=$ koefisien values (2,97)

\section{F. Ground Fault Relay Di GI Sei}

\section{Harapan}

Berikut rangkaian relay ground fault pada GI Sei Harapan.

Gambar 5 Rangkaian relay

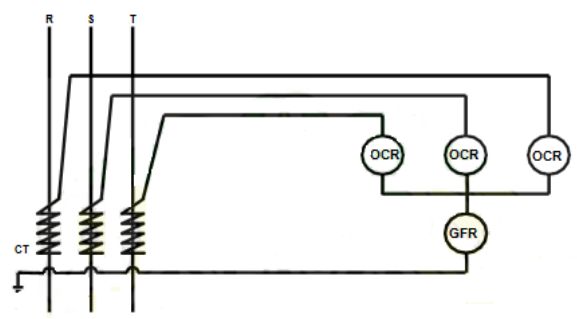

Gambar 6 GFR pada tiga fasa GI Sei Harapan

\section{METODOLOGI PENELITIAN}

\section{A. Alat pengujian}

Alat yang di perlukan untuk penelitian ini adalah SVERKER 780. SVERKER 780 adalah salah satu alat pengujian relai satu fasa yang digunakan oleh engineer. Fitur ini membuat pengujian yang di lakukan lebih efisien dan lebih mudah.

Gambar 7 SVERKER 780

\section{B. Alir Penelitian}

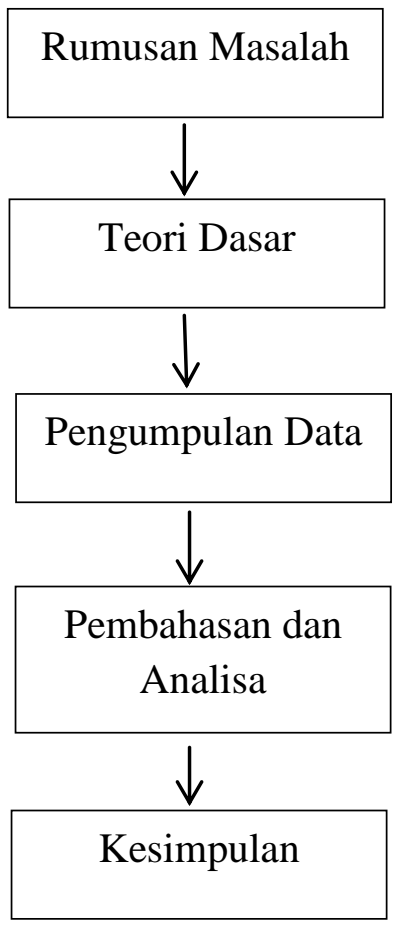

Gambar 8 Alir Penelitian

Dari gambar 3.2 di atas ini dapat di ketahui langkah pertama yang harus di lakukan ialah masalah apa yang akan penulis analisis, teori apa yang akan di gunakan untuk menganalisa masalah tersebut, kemudian pengumpulan data - data yang di gunakan, pembahasan dari permasalahan yang ada, dan terakhir menyimpulkan dari hasil analisa permasalahan tersebut.

\section{Teori Dasar}

Teori dasar yang berhubungan dengan pembahasan ini ditentukan dari nilai arus setting pada relay yang digunakan rumus yaitu :

$$
I s=k . \text { In }
$$

Penentuan karakteristik relay sepam 1000+ dengan standard 
inverse dapat digunakan rumusan yaitu:

$$
\mathrm{t}=\frac{0,14}{\left(\frac{I f}{I s}\right)^{0 / 02}-1} \cdot \frac{T}{2.97}
$$

\section{Pembahasan}

Untuk pembahasan dari rumusan masalah ini, penulis membahas tentang perhitungan waktu tunda kerja relay ground fault menggunakan rumus standard inverse, dan membandingkan hasil pengujian test trip dengan hasil perhitungan menggunakan rumus standard inverse.

Dan data yang di perlukan ialah data hasil pengujian test trip relay ground fault pada feeder cendrawasih di gardu induk sei harapan.

\section{HASIL PEMBAHASAN}

\section{DAN}

\section{A. Spesifikasi Relay Sepam 1000+}

Pada setiap relay mempunya spesifikasi masing - masing, salah satunya relay Sepam 1000+. Spesifikasi relay Sepam 1000+ yang akan digunakan adalah sebagai berikut:

1. Merk Schneider.

2. Type Sepam 1000+.

3. Power Supply (110-120) Volt AC dan (48-250) Volt DC.

4. Tegangan kontak bantu/out (100-240) Volt AC dan (24220) Volt DC.

5. Tegangan Kontak bantu / in (24-250) Volt DC.

6. Frekuensi $(47,5-63) \mathrm{Hz}$

7. Sebagai proteksi gangguan fasa ke tanah.
8. Sebagai proteksi arus lebih.

\section{B. Skematik Rangkaian Test Trip}

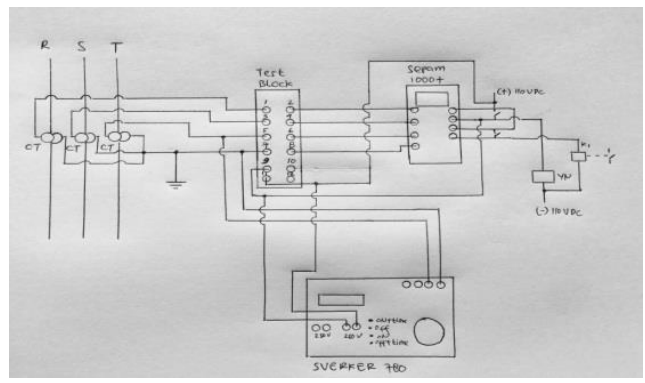

Gambar 9. Skematik rangkaian pengujian test trip relay

\section{Data Pengujian Test Trip Relay Sepam 1000+}

Pegujian relay pada feeder cendrawasih ini dilaksanakan hari jum'at tanggal 09 Juni 2017 jam 10.00. data tersebut dapat di lihat di bawah ini :

Tabel 1 Pengujian test trip pada feeder cendrawasih

\begin{tabular}{|c|c|c|c|c|}
\hline \multirow{2}{*}{ Mata Ujij } & \multirow{2}{*}{ Fasa } & \multicolumn{3}{|c|}{ Arus Injeksi } \\
\cline { 3 - 5 } & & $2 \times \mathrm{Is}(1,5)=3 \mathrm{~A}$ & $\begin{array}{c}3 \times \mathrm{Is}(1,5)=4,5 \\
\mathrm{~A}\end{array}$ & $4 \times \mathrm{Is}(1,5)=6 \mathrm{~A}$ \\
\hline & $\mathrm{R}$ & 0,517 & 0,328 & 0,264 \\
\cline { 2 - 5 } $\begin{array}{c}\text { Waktu } \\
\text { Kerja }(\mathrm{s})\end{array}$ & $\mathrm{S}$ & 0,517 & 0,328 & 0,264 \\
\cline { 2 - 5 } & $\mathrm{T}$ & 0,517 & 0,328 & 0,264 \\
\cline { 2 - 5 } & $\mathrm{N}$ & 0,417 & 0,250 & 0,205 \\
\hline
\end{tabular}

Keterengan :

Ratio CT $=(400 / 5)$ A dan batas setelan $\mathrm{I}_{0}$ pada GFR $120 \mathrm{~A}$, tms 0,1.

$$
\begin{aligned}
& \text { Is }=\frac{I_{0}}{\text { ratio } \mathrm{CT}} \\
& \text { Is }=\frac{120 \mathrm{~A}}{80} \\
& \mathrm{Is}=1,5 \mathrm{~A}
\end{aligned}
$$




\section{Time Multiple Setting (tms)}

Untuk menentukan time multiple setting ini dapat dilakukan dengan menggunakan rumus yaitu :

$$
\begin{aligned}
& \mathrm{tms}=\frac{T}{2.97} \\
& \mathrm{tms}=\frac{0.25}{2.97} \\
& \mathrm{tms}=0.08 \mathrm{~s}
\end{aligned}
$$

\section{E. Waktu Tunda Kerja Relay}

Untuk menganalisa relay bekerja tepat pada waktunya, maka perlu dilakukan perhitungan waktu tundanya sesuai dengan karakteristik standard Inverse. Jadi untuk mengetahui waktu tunda relay $(\mathrm{t})$ ini menggunakan rumus yaitu :

$\mathrm{t}=\frac{0,14}{\left(\frac{I f}{I s}\right)^{0 / 02}-1} \cdot \frac{T}{2.97}$

Analisa dilakukan pada fasa netral saja, dikarenakan untuk mengukur besaran arus yang mengalir ke pentanahan. Besaran arus injeksinya juga dilakukan dengan arus yang berbeda. Arus injeksi ini dianggap sebagai arus gangguan (If). Berdasarkan hasil pengujian dari tabel 4.1, maka diketahui arus gangguannya berbeda. Dengan itu dilakukan perhitungannya sebagai berikut :

1. Perhitungan dengan arus injeksi 3 A pada fasa $\mathrm{N}$.

Diketahui : $\mathrm{T}=0,25 \mathrm{~s}$

$$
\begin{aligned}
\text { If } & =3 \mathrm{~A} \\
\text { Maka, } \mathrm{t} & =\frac{0,14}{\left(\frac{I f}{l s}\right)^{0 / 02}-1} \cdot \frac{T}{2.97} \\
& =\frac{0,14}{\left(\frac{s}{I_{1}}\right)^{0 / 02}-1} \cdot \frac{0,25}{2.97} \\
& =0,3376 \mathrm{~s}
\end{aligned}
$$

2. Perhitungan dengan arus injeksi 4,5 A pada fasa $\mathrm{N}$.

Diketahui : $\mathrm{T}=0,25 \mathrm{~s}$

$$
\begin{aligned}
\text { If } & =4,5 \mathrm{~A} \\
\text { Maka, } \mathrm{t} & =\frac{0,14}{\left(\frac{I f}{I_{s}}\right)^{0 / 02}-1} \cdot \frac{T}{2.97} \\
& =\frac{0,14}{\left(\frac{4,5}{I_{s}}\right)^{0 / 02}} \cdot \frac{0,25}{2.97} \\
& =0,2121 \mathrm{~s}
\end{aligned}
$$

3. Perhitungan dengan arus injeksi 6 A pada fasa $\mathrm{N}$.

Diketahui : $\mathrm{T}=0,25 \mathrm{~s}$

$$
\begin{aligned}
\text { If } & =6 \mathrm{~A} \\
\text { Maka, } \mathrm{t} & =\frac{0,14}{\left(\frac{I f}{I s}\right)^{0 / 02}-1} \cdot \frac{T}{2.97} \\
& =\frac{0,14}{\left(\frac{6}{1, s}\right)^{0 / 02}} \cdot \frac{0,25}{2.97} \\
& =0,1676 \mathrm{~s}
\end{aligned}
$$

Dari hasil perhitungan diatas maka dapat dibuat tabel seperti dibawah ini :

Tabel 2 Hasil perhitungan waktu tunda relay $(\mathrm{t})$

\begin{tabular}{|c|c|c|}
\hline Arus Setting Is (A) & Arus Ganggyan If (A) & Waktu Tunda Relay (s) \\
\hline 1,5 & 3 & 0,337 \\
\hline 1,5 & 4,5 & 0,212 \\
\hline 1,5 & 6 & 0,167 \\
\hline
\end{tabular}

\section{F. Perbandingan Hasil Pengujian Dengan Hasil Perhitungan}

Dari pengumpulan data - data pada sub bab sebelumnya, dapat di bandingkan hasil pengujian dengan hasil perhitungan. Berikut perbandingannya : 
Tabel 3 Perbandingan hasil pengujian dengan hasil perhitungan

\begin{tabular}{|c|c|c|c|}
\hline $\begin{array}{l}\text { Arus injeksi } \\
\text { (A) }\end{array}$ & $\begin{array}{c}\text { Hasil Pengujian } \\
\text { (s) }\end{array}$ & $\begin{array}{c}\text { Hasil Perhitungan } \\
(\mathrm{s})\end{array}$ & Selisih \\
\hline 3 & 0,417 & 0,337 & $0,08 \mathrm{~s}$ \\
\hline 4,5 & 0,250 & 0,212 & $0,038 \mathrm{~s}$ \\
\hline 6 & 0,205 & 0,167 & $0,038 \mathrm{~s}$ \\
\hline
\end{tabular}

Dari tabel di atas selisih antara hasil pengujian dan hasil perhitungan menggunakan rumus standard inverse ini rata - rata kecil yaitu di bawah 1 second. Jadi dapat di nyatakan bahwa relay tersebut masih bekerja dengan baik sesuai dengan kurva karakteristik relay. Dan relay tersebut masih layak digunakan pada feeder cendrawasih di gardu induk Sei Harapan.

\section{KESIMPULAN SARAN}

\section{A. Kesimpulan}

Setelah dilakukan penelitian ini, dapat di simpulkan bahwa relai pentanahan dengan type sepam 1000+ pada feeder cendrawasih masih layak digunakan. Karena selisih hasil pengujian dengan hasil perhitungan kurang dari 1 second sesuai dengan karakteristik standard inverse yang telah di terapkan oleh PT. XYZ Batam.

\section{B. Saran}

Adapun saran penulis terhadap PT. XYZ Batam ialah untuk lebih meningkatkan kualitas pelayan dan kehandalan peralatan, sebaiknya untuk pengujian sistem kerja relai - relai proteksi dilakukan secara terjadwal.

\section{DAFTAR PUSTAKA}

[1] Anonim, Protection and Control.sepam range.sepam $1000, \mathrm{~S} 25, \mathrm{~S} 26$ and S35,S36 Installation Use Commissioning, General Characteristick.Scheider Electric, 1999.

[2] Fikri Ahmadsyah, Operasi Terpisah Di Sub Sistem Gardu Induk Batu besar Untuk menghindari Pemadaman Total pada sistem kelistrikan PLN Batam.Batam, Univesitas Riau Kepulauan, 2010.

[3] L.Tobing Bonggas, Peralatan Tegangan Tinggi, Jakarta, 2003.

[4] PLN Persero, Draft Pedoman O\&M, Jakarta, 2010.

[5] Purba Agus, Proteksi Pada Transmisi Tenaga Listrik, aguspurbaproteksi.blogspot.co.id, (02 Juni 2012), \{11 Juni 2017\}.

[6] Stevenson, WD, Analisa Sistem Tenaga Listrik, Jakarta, Erlangga, 2008 . 